\title{
MIKHAIL BAKHTIN, PAUL RICOEUR E HANNAH ARENDT: DIÁLOGOS EM TORNO DO ESPAÇO PÚBLICO E DAS LINGUAGENS
}

\author{
MIKHAIL BAKHTIN, PAUL RICOEUR AND HANNAH ARENDT: \\ DIALOGUES ON THE PUBLIC SPACE AND LANGUAGES
}

\author{
Adna Candido de Paula* \\ Cristine Gorski Severo ${ }^{* *}$
}

RESUMO:Esteartigotemporobjetivoapresentar,demaneirainterdisciplinar, reflexões acerca da relação entre espaço público e linguagens. Trata-se de abordar o tema a partir: (i) das noções bakhtinianas de enunciado, significação, mundo da vida, mundo da cultura, responsabilidade e ética; (ii) das concepções ricoeurianas de atos de fala, de configuração do mundo habitável, da dupla estrutura da identidade, enquanto idem e ipse, da relação entre identidade e alteridade e da dimensão ética das narrativas ficcionais. Algumas dessas noções são aproximadas às definições de Arendt acerca do espaço público e do papel do discurso e da ação nesta esfera. Finalizando, o conceito de espaço público possibilita a discussão de uma certa concepção de ética, vinculada à relação (dialógica) dos sujeitos com a alteridade.

PALAVRAS-CHAVE: discurso, espaço-público, linguagens, ética.

ABSTRACT: This article aims at presenting, in an interdisciplinary way, reflections on the relation between the public space and languages. For this purpose, we shall discuss the following topics: (i) from Bakhtin's perspective, the notions of: utterance, meaning, the world of life, the world of culture, responsibility and ethics; (ii) from Ricqueur's perspective, conceptions of: speech acts, the configuration of the habitable world, the double structure of the identity - as idem and ipse -, the relation between self identity and otherness, and the ethical dimension in fictional narratives. Some of these notions are related to Arendt's definitions of the public sphere and the role of discourse and action in this sphere. To conclude, the notion of public space leads us to a discussion of a certain conception of ethics connected to the (dialogic) subject-other relations.

KEYWORDS: discourse, public space, languages, ethics.

* Professora Doutora e Pós-doutora pela Universidade Estadual de Campinas. Professora Adjunto I da Universidade Federal da Grande Dourados - Dourados (MS). Líder do Grupo de Pesquisa CNPq "Estudos Interdisciplinares de Literatura e Teoria Literária”. adnapaula@yahoo.com.br.

* Professora Doutora pela Universidade Federal de Santa Catarina. Professora Adjunto I da Universidade Federal de São Carlos - São Carlos (SP). Líder do Grupo de Pesquisa CNPq "Discursos e Identidades: Questões de Política e Ética”. crisgorski@gmail.com. 



\section{INTRODUÇÃO}

O presente artigo representa uma oportunidade há tempos aguardada pelas autoras para que pudessem problematizar e articular em conjunto temas que estudam em particular. Com a proposta "Espaço público e Linguagens" a Associação Nacional de Pós-graduação e Pesquisa em Letras e Linguística possibilitou a reunião de tópicos compartilhados pelos filósofos Hannah Arendt e Paul Ricoeur, que são aproximados a certos temas presentes na filosofia dialógica e discursiva de Mikhail Bakhtin (e seu Círculo).

Sucintamente, o espaço público é visto como o locus de circulação dos discursos, dos gêneros discursivos, de atos de linguagem e de práticas sociais variadas, onde os sujeitos estabelecem relações dialógicas entre si e com o seu objeto discursivo. Tais relações - que se fundam em uma interação com a alteridade - são participantes, por um lado, do processo de constituição de suas identidades e, por outro, do processo de produção de sentidos e de interpretações, produzindo efeitos sobre a ação dos sujeitos no mundo.

Para discutir a relação entre o espaço público e as linguagens, este artigo propõe uma articulação teórica entre certos conceitos presentes nos trabalhos de Bakhtin, de Ricoeur e de Arendt. A aproximação entre esses três filósofos se dá em torno de uma certa concepção de esfera pública vinculada a questões como: processos de significação e de interpretação; 
circulação dos discursos e atos de linguagem; e relações (dialógicas) entre os processos de constituição das identidades e a alteridade. A aproximação teórica entre tais autores evidencia temas que atravessam uma concepção de ética, tais como: certa ideia de liberdade e de singularidade, o papel do discurso e a possibilidade de ação (e de criação do novo) na esfera pública e a responsabilidade.

O artigo está estruturado em três seções: (i) atos de linguagem, diálogo e discurso; (ii) ideologias, espaço público e identidades; (iii) dimensões éticas das linguagens. Apesar de outros autores fazerem parte dessa rede dialógica, como Stuart Hall e Zygmunt Bauman, o foco da discussão recai sobre as obras dos três filósofos supracitados.

\section{DISCURSO, DIÁLOGO E ATOS DE LINGUAGEM}

Esta exposição inicia-se com as noções de discurso e de enunciado na abordagem bakhtiniana. Em seguida, apresenta-se a abordagem dialógica e a relação intrínseca que ela tem, por um lado, com os discursos e, por outro, com aquilo que Bakhtin chama de mundo da vida, entendido como o espaço concreto e real de produção e de circulação dos discursos (enunciados) e dos gêneros discursivos. Finalizando a seção, serão apresentadas a relação estudada por Ricoeur entre os atos de fala e a sobreposição da teoria do texto na teoria da ação, e a configuração do que o filósofo denomina mundo habitável.

Uma série de oposições teóricas atravessa os trabalhos de Bakhtin. Este texto abordará várias dessas oposições. Dentre elas, encontram-se as noções de enunciado e de tema se contrapondo às noções de frase e de significação, respectivamente. Quanto ao enunciado, esse pode ser entendido basicamente como a unidade da comunicação discursiva, diferente da frase/oração, tida como unidade gramatical e estrutural do sistema da língua e que, diferente do enunciado, não se vincula ao contexto extraverbal ou às enunciações dos demais interlocutores. Segundo Bakhtin (2003b), os enunciados não são unidades independentes e autônomas, mas constituem elos em uma cadeia da comunicação discursiva, habitando as fronteiras entre os discursos próprios e os discursos alheios. A sua relativa unidade se dá pela alternância dos sujeitos do discurso, o que implica a ideia de que apenas a réplica em um dado estado de conclusibilidade do enunciado provoca uma reaçãoresposta no interlocutor; é essa sensação de acabamento e de inteireza do tema que pode suscitar uma resposta. Tal sensação é determinada, segundo Bakhtin (2003b), pelo esgotamento (temporário) do tema, pela intenção discursiva do sujeito e pelas características do gênero discursivo utilizado. 
Os enunciados se organizam em formas relativamente estáveis de discurso na interação socioideológica, que definem os gêneros discursivos. Estes são heterogêneos e definem historicamente uma certa forma de percepção e de interação com a realidade socioideológica. Eles podem ser primários ou secundários, sendo que os primeiros se constituem na comunicação discursiva imediata, refletindo amplamente as ideologias do cotidiano; os segundos são reelaborações dos primeiros e se caracterizam por serem complexos e fruto de elaborações culturais mais desenvolvidas e organizadas. A compreensão do vínculo existente entre linguagem e ideologia repousa na relação que há entre os gêneros primários e secundários e na formação histórica destes últimos (BAKHTIN, 2003b).

O estudo do enunciado, segundo Bakhtin e Voloshinov (1988), deve levar em conta uma série de características: (i) sua determinação pelo contexto social imediato; (ii) seu direcionamento a um locutor (mesmo que não seja real); (iii) sua relação com o horizonte sócio-histórico e ideológico; (iv) sua vinculação aos sujeitos do discurso e à avaliação destes. Os enunciados carregam valores semânticos que não se limitam aos significados dicionarizados ou cristalizados de uma dada cultura ou época, mas se tratam de sentidos ideológicos, singulares e únicos, ou seja, do tema, que é determinado tanto pelas formas linguísticas quanto pelos elementos extraverbais da interação.

Sucintamente, o tema, sendo constitutivo do signo e/ou da manifestação verbal, necessariamente possui um índice de valor social, e pode ser entendido como o sentido do enunciado concreto, único, individual, dependente da situação histórica concreta, impossível de ser submetido à análise fragmentária e, fundamentalmente, opera como resposta a outros enunciados, por isso, requer uma compreensão ativa. A significação, fundada na convenção, difere do tema quanto ao seu caráter repetível, idêntico e abstrato. Em outras palavras: a significação associa-se aos elementos linguísticos, e o tema vincula-se à situação histórica real de comunicação verbal, sendo que "o tema deve apoiar-se sobre uma certa estabilidade da significação; caso contrário, ele perderia o seu elo com o que precede e o que segue, ou seja, ele perderia, em suma, o seu sentido" (BAKHTIN; VOLOSHINOV, 1988: 129).

As distinções entre enunciado e frase, por um lado, e tema e significação, por outro, constituem a base da concepção dialógica e bakhtiniana da linguagem. A concepção dialógica da linguagem se fundamenta em um entendimento da língua como enunciado; sendo assim, os sentidos não são 
cristalizados ou fechados, mas são construídos/retomados/expandidos/ desestabilizados no processo de interação em um dado contexto sóciohistórico-ideológico. Os sujeitos, nesse caso, não interagem verbalmente usando as palavras da língua (do sistema), mas sim as palavras circulantes pelo mundo da vida, que carregam valorações sociais diversas e que estabelecem relações de sentido com outras palavras ou enunciados. Essa relação de sentido se pauta na ideia de dialogismo, inerente à concepção de enunciado.

A dialogicidade interna do discurso invoca a pluralidade de vozes presentes num texto-enunciado; tais vozes estabelecem entre si relações variadas de, por exemplo, retomada, paráfrase, paródia, censura, ironia, negação, divergência, convergência, conflito etc. Tais relações se inscrevem em movimentos tanto centrípetos quanto centrífugos, produzindo efeitos de monologização (como as vozes de autoridade) e de dialogização (como as vozes internamente persuasivas) (BAKHTIN, 1998).

Sistematizando, é possível elencar três níveis de dialogismo na língua (BAKHTIN, 1998; 2003b): (i) O endereçamento do enunciado a alguém (e a sua atitude-responsiva): o enunciado tem autor e destinatário, sendo este tido como alguém que compreende e responde os enunciados de forma ativa, integrando um diálogo vivo com os sentidos (temas) dos enunciados e não com o significado cristalizado das enunciações. Os enunciados destinam-se ao fundo apreciativo dos interlocutores, o que significa que suas respostas são coloridas expressivamente. As concepções do destinatário são determinadas pela esfera da atividade humana (e da vida) à qual o enunciado se refere. (ii) A relação dos enunciados com enunciados já-ditos e com as respostas antecipadas. Assim, por mais monológico - concentrado no seu objeto - que um enunciado tenda a ser (como os enunciados científicos), ele também é uma resposta aos enunciados anteriores sobre este objeto, ou uma reação-resposta aos enunciados que estão por vir. (iii) A relação do enunciado com o objeto discursivo, ou seja, as variadas intenções e orientações dos sujeitos sobre o objeto povoam esse objeto com discursos alheios, pontos de vista, valorações e entonações variadas.

Os gêneros discursivos complexos são originários, como indicado acima, dos gêneros simples, como os diálogos e a interação face a face. Paul Ricoeur, assim como Bakhtin, dedicou-se ao estudo dos gêneros discursivos simples a fim de aí identificar elementos primários que legitimam a relação dialética entre a teoria da ação e a do texto. O início dessa articulação levou em consideração os atos de linguagem performativos estudados por John Austin e John Searle. Estes atos são aqueles que produzem ação e precisam 
de condições para que a ação se efetue. Para este fim é necessário, portanto, um equilíbrio entre as funções e as condições de comunicação (BAKHTIN, 2003a). Os atos performativos se dividem em: (i) locucionários, que é a operação predicativa, ou seja, "dizer algo sobre alguma coisa", é também o ato de fala propriamente dito; (ii) ilocucionários, aquele que se realiza na linguagem, faz algo ao dizer, e em que a intenção do locutor é explícita, como nas declarações matrimoniais: "eu prometo ser fiel, na saúde e na doença"; (iii) interlocucionários, que pressupõem a presença do interlocutor, para que haja ilocução e (iv) perlocucionários, os atos que não se realizam na linguagem, mas pela linguagem, ou seja, é a ação-reação do interlocutor. Os atos perlocucionários não são intencionais e necessitam do reconhecimento do interlocutor. No primeiro momento de interlocução, o contexto do texto tem papel fundamental no processo de filtragem da polissemia da mensagem, procedimento necessário para reduzir a pluralidade das interpretações. Reduzir, nesse caso, não é eliminar completamente o caráter polissêmico das palavras, mas assegurar a interpretação. $\mathrm{O}$ diálogo entre locutor e interlocutor define o contexto da comunicação e é ele, o contexto, que reduz o campo do mal-entendido.

A ênfase no estudo dos atos de linguagem, dentro da filosofia ricoeuriana (RICOEUR, 2000), está centrada em uma dupla contribuição destes, (i) por ser a própria linguagem o processo pelo qual a experiência privada se torna pública e (ii) pela relação objetiva entre fala e ação dos atos ilocucionários e perlocucionários, pois aí está, segundo Ricoeur, a unidade mínima da dialética do sentido e da referência, que é índice da relação entre a linguagem e a condição ontológica do ser-no-mundo. Segundo Ricoeur, "a linguagem não é um mundo próprio. Nem sequer é um mundo. Mas, porque estamos no mundo, porque somos afetados por situações e porque nos orientamos mediante a compreensão em tais situações, temos algo a dizer, temos a experiência para trazer à linguagem" (2000:32). A experiência disposta no discurso e a relação entre dizer-fazer do diálogo são articuladas por Ricoeur em sua proposição da dialética entre texto e ação.

No capítulo "Le modele du texte: l'action sensée considérée comme un texte", do livro $\mathrm{Du}$ texte à l'action, Ricoeur propõe a questão: "Em que medida podemos considerar a noção do texto como um paradigma apropriado de objeto das Ciências Sociais?"' A questão de Ricoeur

\footnotetext{
${ }^{1}$ A tradução de todos os trechos da obra de Paul Ricoeur, citados neste artigo, é de nossa responsabilidade.
} 
estabelece a relação interpretação-ação-texto que é fundamental para se compreender a dimensão ideológica impressa nos discursos. A fim de responder a essa questão faz-se necessário considerar que é no discurso que a função simbólica da língua é atualizada. O discurso refere um mundo que ele pretende descrever, exprimir, representar. O mundo é o conjunto de referências abertas pelo texto (RICOEUR, 1986: 211). Ricoeur propõe um pequeno ajuste na definição de Max Weber do objeto das Ciências Humanas - "conduta orientada de maneira sensata [racional]" - para "conduta orientada por caracteres de lisibilidade" (1986: 213). Nessa apreensão, a ação inteligível torna-se objeto das Ciências Sociais somente sob a condição de um tipo de objetivação equivalente à fixação do discurso pela escrita. Para Ricoeur, a ação constitui uma configuração que demanda ser interpretada em função de suas conexões internas. Isso porque "alguns traços internos da ação a aproximam da estrutura dos atos de linguagem, que transformam o fazer em um tipo de enunciação (1986: 213-214). A compreensão da ação enquanto ato de linguagem permite que ela seja identificada não somente em função do seu conteúdo proposicional, mas também em função da sua força ilocucionária [quando dizer é fazer]. Em consequência dessa interpretação da ação como texto tem-se a equivalência de autonomia da ação e do texto em relação aos seus respectivos autores, o que potencializa ambas em suas capacidades de descontextualização e recontextualização. A inscrição da ação humana no texto desenvolve significações que podem ser atualizadas e interpretadas em outros contextos, em situações diferentes da original. Nesse sentido, a ação enquanto texto transcende as condições sociais de sua produção e pode ser reefetuada em novos contextos sociais. Sua importância consiste em sua pertinência onitemporal.

A história da civilização é uma narrativa de ações relevantes, aquelas que imprimem sua marca no tempo e só o podem fazer porque estão inscritas no discurso. $\mathrm{O}$ que equivale a dizer que existe uma ausência significativa das ações que não estão presentes nos textos da humanidade, históricos, religiosos, literários, políticos etc. Segundo Ricoeur, uma ação deixa um traço, ela imprime sua marca, quando contribui para a emergência de configurações, que se tornam os documentos da ação humana. Por outro lado, essa inscrição da ação no discurso também possibilita o julgamento, ou a condenação, das ações reprováveis, como, por exemplo, aquelas que permitiram a Shoah, as ditaduras, os genocídios das guerras civis e militares. Quando se tornam texto, essas ações entram para o dossiê da humanidade. Em um âmbito mais restrito, há os dossiês informais ou públicos que são 
conservados em arquivos, cartórios, escola, banco, polícia, etc. Para Ricoeur, existe um análogo informal desses dossiês que nós chamamos de reputação e que constitui a base para a condenação.

Finalizando, tanto Bakhtin como Ricoeur amarram suas concepções de linguagem (discurso, atos de fala) ao mundo real e concreto em relação ao qual as enunciações assumem um sentido único, singular e irrepetível. Nesse caso, a noção de significação não se reduz a uma concepção gramatical, literal e cristalizada, mas relaciona-se à possibilidade de abertura dos sentidos, ou seja, os sentidos, no curso da história ou em relação a diferentes contextos socioverbais, podem despertar, renascer, transformar-se ou serem apagados, promovendo, assim, novas possibilidades de interpretação do mundo e, por tabela, das ações dos sujeitos no mundo. Nas palavras de Bakhtin: "Em cada cultura do passado estão sedimentadas as imensas possibilidades semânticas, que ficaram às margens das descobertas, não foram conscientizadas nem utilizadas ao longo de toda história de uma dada cultura" (2003a: 364-65). A seguir, abordam-se, entre outras, a noção de sentido/significação e a relação dela com uma certa concepção de espaço público.

\section{IDEOLOGIAS, ESPAÇO PÚBLICO E IDENTIDADES}

Esta seção aborda a concepção bakhtiniana de ideologia(s) relacionada, por um lado, à dimensão concreta e material de uso da linguagem e, por outro, à noção de sentido. Atrelado a esse tema, depreende-se dos trabalhos de Bakhtin uma certa concepção de espaço público - associada à ideia de mundo da vida, de ética e do "carnaval" (Rabelais) -, que é aproximada da noção de esfera pública presente nos trabalhos de Arendt. Ademais, apresenta-se a noção de espaço público - associada à questão das identidades idem e ipse e da alteridade - conforme entendida por Ricoeur.

Os gêneros e discursos circulam por aquilo que Bakhtin chama de mundo da vida, entendido como o espaço concreto e real de produção e de circulação dos discursos e dos gêneros discursivos, compreendendo tanto as esferas privadas como públicas. Essa noção se opõe ao mundo da cultura, tido como o espaço da produção cognitiva, racional, abstrata e, portanto, de caráter universal, reiterável, estável, cristalizado e neutro. Essa oposição se remete, nos trabalhos do Círculo de Bakhtin (1988; 2003b), à oposição estabelecida entre significação e tema, estando ambos apoiados em uma dada concepção semântica e discursiva, conforme visto na seção anterior. Antes de passarmos ao assunto da ideologia, cabe desmembrar a noção de 
mundo da vida (e da cultura), para Bakhtin, dado que essa noção vinculase, por um lado, à questão do espaço público e, por outro, à questão ética.

Bakhtin, em um de seus trabalhos iniciais (1919-1921), discute filosoficamente as três atividades humanas: cognição, estética e ética, sendo as duas primeiras associadas ao mundo da cultura e a terceira, ao mundo da vida. A cognição estaria vinculada à relação mental (reflexiva) das pessoas com o mundo, à atribuição de sentidos válidos e verdadeiros aos eventos da vida - o que ocorre por meio da dimensão científica. A segunda se ligaria à relação afetiva dos sujeitos com o mundo, que englobaria a dimensão artística. A terceira estaria comprometida com a ação responsável, a ética, ou seja, as dimensões social e política. Dessa forma, as atividades cognitivas (científicas) e estéticas vinculam-se a uma certa prática de objetivação do mundo, não podendo ser vistas como uma totalidade da realidade concreta, dado que apagam a possibilidade do imprevisível, do acontecimento e do devir.

É apenas no mundo da vida que os atos únicos e singulares existem, onde a linguagem toma contato com a vida na forma de enunciado (discurso), onde os sentidos assumem um caráter também singular, irrepetível e concreto. Assim, é em relação a esse mundo, por um lado, que o mundo da cultura é definido e estruturado e, por outro, que as possibilidades de ressignificação, de novidade e de mudança linguística tomam forma, dado que é o espaço próprio de existência da pluralidade discursiva (heteroglossia), segundo a qual, existem infinitas línguas ideológicas (do operário, do médico, do judeu, do estudante, do ucraniano, da literatura canônica, do romance etc.) que interagem entre si. Tal inter-relação é regida por duas forças antagônicas: uma que visa apagar as variadas línguas em nome de uma língua única e outra que visa a estratificação e as contradições. (BAKHTIN, 1998)

Ao afirmar que se pode "estudar a evolução semântica, isto é, a história da ideologia no sentido exato do termo" (1988: 114), Bakhtin e Voloshinov deixam muito clara a relação entre sentido (o tema) e ideologia, uma vez que o sentido existe apenas em relação ao contexto ideológico e prático, ou seja, ao mundo da vida. É nesse mundo que diferentes ideologias se confrontam, se complementam, se contradizem, se reforçam etc., estabelecendo entre si relações dialógicas. É no mundo da vida que existe o espaço público, ou seja, é no mundo concreto das relações dialógicas e de poder estabelecidas entre os sujeitos, os discursos, as formas sócio-históricas verbais de comunicação, num caldeirão heterogêneo e plural de vozes, que tanto a reprodução dos sentidos e das práticas discursivas como a possibilidade de emergência do novo e do singular coexistem. As ideologias circulantes pela esfera pública 
do mundo da vida compreendem tanto as ideologias do cotidiano como os sistemas ideológicos constituídos, sendo que aquelas alimentam essas, ou seja, as ideologias do cotidiano são a base a partir da qual as teorias, as objetificações e as representações do mundo se constroem e se configuram. Note-se que as ideologias do cotidiano e as esferas ideológicas (religião, direito, ciência etc.) - estabelecendo um paralelo com os gêneros primários e secundários - não existem como entidades autônomas e independentes, mas estabelecem entre si uma relação dialógica (e dialética):

Os sistemas ideológicos constituídos da moral social, da ciência, da arte e da religião cristalizam-se a partir da ideologia do cotidiano, exercem por sua vez sobre esta, em retorno, uma forte influência e dão assim normalmente o tom a essa ideologia [...] ao mesmo tempo, esses produtos ideológicos constituídos conservam constantemente um elo orgânico vivo com a ideologia do cotidiano (BAKHTIN; VOLOSHINOV, 1988: 119).

Nesse sentido, os produtos culturais elaborados, que atravessam e caracterizam certas formas de interação socioverbal mais cristalizadas ou oficiais, emergem do mundo da vida cotidiana. A esfera pública, enquanto espaço de visibilidade de circulação e de produção de certos discursos, gêneros discursivos e práticas sociais, é constituída e atravessada pela ideologia do cotidiano. Nesse sentido, é nesse espaço que tanto as ideologias oficiais se elaboram e se transformam, como as mudanças discursivas (semânticas) e sociais ocorrem. No processo de mudança (social, política, religiosa, cultural, linguística), a palavra, segundo Bakhtin e Voloshinov (1988), assume papel importante na revelação das transformações sociais e semânticas - inclusive aquelas que ainda não foram "absorvidas" pelos sistemas ideológicos elaborados -, visto que ela, enquanto signo neutro, é plástica e se faz presente nos processos de compreensão e produção discursiva, sendo, portanto, capaz de assimilar e preencher qualquer função ideológica.

Mais especificamente acerca da esfera pública, o trabalho de Bakhtin sobre Rabelais (2002) traz à tona a maneira pela qual as festas populares na Idade Média - o carnaval, os espetáculos ao ar livre e as feiras -, que se realizavam nas ruas e praças públicas, operavam como uma forma de abertura e de desestabilização do poder oficial e vigente (os sistemas ideológicos estruturados) ao apagar as distinções hierárquicas, suspender certas normas estatais e religiosas e promover a experiência de liberdade e de igualdade entre os indivíduos. O carnaval, como festividade pública, 
produzia a possibilidade de circulação de determinados discursos e formas de comunicação verbal que, fora desse contexto, eram proibidas ou censuradas. Assim, a linguagem carnavalesca, "autorizada" sob determinadas circunstâncias, era uma linguagem politizada, no sentido de estremecer, desestabilizar, parodiar, ironizar etc. as ideologias oficiais. Essa linguagem, segundo Bakhtin, caracterizava-se "pela lógica original das coisas 'ao avesso', 'ao contrário', pelas permutações constantes do alto e do baixo ('a roda'), da face e do traseiro, e pelas diversas formas de paródias, travestis, degradações, profanações, coroamentos e destronamentos bufões" (2002: 10). A percepção, a linguagem e a ideologia carnavalesca instauravam a possibilidade de ressignificação e de surgimento de outras formas de vida e de visão de mundo; tratava-se, sobretudo, de uma prática de resistência ao poder hierárquico e às ideologias oficiais através da forma coletiva, ambivalente e bivocal do riso carnavalesco. Nas palavras de Bakhtin:

A praça pública no fim da Idade Média e no Renascimento formava um mundo único e coeso onde todas as "tomadas de palavra" (desde as interpelações em altos brados até os espetáculos organizados) possuíam alguma coisa em comum, pois estavam impregnados do mesmo ambiente de liberdade, franqueza e familiaridade (2002: 132).

As ideias de liberdade e do caráter não-oficial da praça pública carnavalesca na Idade Média e no Renascimento encontram ressonância, em certo sentido, nos trabalhos de Hannah Arendt (2005) sobre o espaço público (especialmente sobre a polis grega) como local de circulação de discursos e práticas de natureza política. Segundo a autora, a esfera pública (em oposição à esfera privada) diz respeito, sucintamente, (i) ao que pode ser visto e ouvido por todos, com ampla divulgação; (ii) ao mundo comum a todos e que reúne e mantém o vínculo e a relação entre os indivíduos. Diferentemente da ideia de sociedade de massa - na qual os indivíduos convivem entre multidões sem estarem necessariamente em relação entre si - a esfera pública abrange o convívio das pessoas em um mundo comum, com o qual elas se vinculam (ou se separam), se relacionam e pelo qual elas demonstram interesse. Trata-se de um espaço onde "ser visto e ouvido por outros é importante pelo fato de que todos vêem e ouvem de ângulos diferentes (ARENDT, 2005: 67)".

Essa característica de singularidade dos sujeitos, em que cada um ocupa um lugar diferente e único no mundo da vida (ou na esfera pública), só é possível num mundo plural, marcado tanto pela igualdade (que garante 
a compreensão mútua) como pela diferença (a alteridade). As ideias de singularidade e de alteridade constituem também a perspectiva bakhtiniana de mundo da vida, tido como o mundo onde os atos individuais, singulares e dialógicos dos sujeitos são realizados e objetivados, ou seja, "o único mundo onde nos criamos, conhecemos, contemplamos, vivemos nossas vidas e morremos" (BAKHTIN, 1993: 20). A articulação entre identidade e alteridade é o centro da configuração do mundo habitável postulado por Paul Ricoeur e é, também, a base da orientação ética presente nos discursos, sobretudo nas narrativas ficcionais, como se verá adiante.

A esfera pública, nos trabalhos de Arendt, é o espaço próprio da liberdade e é através dos atos e discursos que os sujeitos se diferenciam e se singularizam nesse espaço. Assim, a inserção do homem no mundo público se dá pelas palavras e pelos atos - o agir entendido como iniciar e tomar a iniciativa - e não motivada pela necessidade biológica ou pela utilidade (produção de objetos pelo trabalho). A possibilidade do novo surge dos atos e discursos de homens singulares e plurais inscritos na esfera pública. O discurso não se desvincula da ação, conforme exposto segundo as ideias de Paul Ricoeur, ao contrário, ele é a condição de sobrevivência desta, é a sua condição de possibilidade: "embora o ato possa ser percebido em sua manifestação física bruta, sem acompanhamento verbal, só se torna relevante através da palavra falada na qual o autor se identifica, anuncia o que fez, faz e pretende fazer" (ARENDT, 2005: 191).

Essa revelação das identidades dos sujeitos pelo discurso ocorre na relação com outros sujeitos, ou seja, no âmbito de um espaço compartilhado. $\mathrm{O}$ ato, para que possa promover a novidade e deixe de ser apenas atividade produtiva, depende dessa revelação. A ideia de instauração da novidade em um espaço público de liberdade mediante o uso da linguagem pode ser também encontrada nos trabalhos de Bakhtin sobre Rabelais e a cultura popular medieval (o carnaval das praças públicas). A linguagem utilizada nessas festividades representava "tudo o que é diretamente ligado à vida da praça pública, que traz a marca do caráter não-oficial e da liberdade da praça pública" (BAKHTIN, 2002: 132). Sobre a novidade,

O carnaval [...] liberava a consciência do domínio da concepção oficial, permitia lançar um olhar novo sobre o mundo; um olhar destituído de medo, de piedade, totalmente crítico, mas ao mesmo tempo positivo e não niilista, pois descobria o princípio material e generoso do mundo, o devir e a mudança, a força invencível e o triunfo eterno do novo, a imortalidade do povo (2002: 239). 
Essa liberdade, ou a sua aparência, garantida pelo espaço público encontra ressonância na configuração do mundo habitável postulado por Paul Ricoeur. Ao filósofo importa a referência do enunciado metafórico enquanto poder de redescrever [redécrire] a realidade: "A metáfora se apresenta então como uma estratégia de discurso que, preservando e desenvolvendo a potência criativa da linguagem, preserva e desenvolve o poder heurístico manifesto pela fiç̧ão" (RICOEUR, 1975: 10). A inovação semântica da metáfora, quando esta se configura em linguagem narrativa dentro do enredo ficcional, evoca o caráter polissêmico desse enredo que, heuristicamente, representa um mundo habitável. A configuração do mundo habitável que é manifesto pela leitura do enredo da narrativa ficcional, dentro da hermenêutica ricoeuriana, tem como fundamento a questão da temporalidade que só pode ser reconhecida e interpretada quando disposta em narrativa, visto que, como afirmou Agostinho em Confissões, a temporalidade humana é a temporalidade narrada. Tendo em vista que a redescrição metafórica destaca-se no campo do páthos, dos valores sensoriais, estéticos e axiológicos, que estruturam o mundo habitável, percebe-se que a função mimética das narrativas se exerce de preferência no campo da ação e de seus valores temporais (RICOEUR, 1975). É a partir dessa constatação que Ricoeur postula a tríplice mimesis estruturada em três fases. A primeira mimesis é a pré-figuração, ou seja, é a pré-compreensão comum do mundo que Gadamer considerou como pré-concepção presente, e atuante, no ato interpretativo. A segunda mimesis é a configuração, trata-se ainda da recepção e do ato de depreensão e compreensão do agenciamento dos fatos, ou seja, das ações, e do seguimento dessas até a peripécia, ou seja, a mudança de fortuna. Ao agenciamento dos fatos Ricoeur denomina de concordância e aos reveses discordância. A configuração é o intermédio entre a pré-figuração e a refiguração que representa a terceira mimesis. É na refiguração que se dá a junção entre o mundo do texto e o mundo do leitor, visto que é no ato de leitura que esse primeiro se manifesta. Paul Ricoeur é filósofo e está preocupado em identificar um equivalente heurístico do mundo, onde haja sujeitos, ações, escolhas, temporalidade, espacialidade, agenciamentos dos fatos, enfim, uma estrutura heurística para se pensar o "ser sendo" - Dasein. Nesse sentido, as narrativas ficcionais são exemplares por configurarem um mundo habitável, mas os elementos suscitados por Ricoeur, com a diferença do distanciamento estético que, através da suspensão da descrença, permite a identificação-com, estão presentes em todo e qualquer texto: identidade-idem, identidade-ipse, temporalidade 
narrada, troca de experiências, paradigmas de escolhas, ações em texto passíveis de julgamento, pertencimento e implicações éticas.

Seja como mundo da vida (Bakhtin) ou mundo habitável (Ricoeur), é na linguagem que o jogo entre o sujeito (identidade) e o outro (alteridade) tem lugar. É nessa dimensão da linguagem como locus privilegiado da relação entre identidade e alteridade que a filosofia de Paul Ricoeur pode ser compreendida em três focos de investigação: (i) da dupla estrutura da identidade pessoal, que só pode ser articulada na dimensão temporal da existência humana; (ii) da teoria narrativa em sua contribuição para com a constituição do "si"; (iii) na compreensão do sujeito que é capaz de se designar a si próprio, expressando o mundo, dentro do enunciado e/ou narrativa ficcional, como sujeito da imputação moral. Dos três focos, os dois primeiros estão diretamente ligados à compreensão da ideologia e do espaço público, cujo ponto comum de articulação é a identidade.

A identidade pessoal deve ser compreendida em sua dupla estrutura, como identidade mesmidade e como identidade ipseidade. Ambas são formas de permanência no tempo. O radical da primeira é o idem, que faz essa identidade ser entendida no quadro da comparação, ela está relacionada ao idêntico, ao imutável. Trata-se da identidade numérica, quantitativa, é a reidentificação do mesmo, em que conhecer equivale a reconhecer. A palavra de ordem da identidade-mesmidade é o caráter: "conjunto das marcas distintivas que permitem reidentificar, reconhecer um indivíduo como o mesmo" (RICOEUR, 1991: 144). O caráter é a mesmidade na totalidade da existência. Segundo Ricoeur, a identidade de uma pessoa e de uma comunidade "é feita dessas identificações-com valores, normas, ideais, modelos, heróis, nos quais a comunidade se reconhece. O reconhecer-se no contribui para o reconhecer-se com" (1991: 147). A identidade-mesmidade é o suporte para o acesso à identidade-ipseidade, cujo radical latino ipse traduz outro tipo de permanência no tempo. Para essa identidade, a palavra de ordem é a promessa. Trata-se da identidade qualitativa representada pela manutenção da palavra dada. A forma de permanência no tempo da identidade-ipseidade é a resposta à pergunta o que sou eu? A resposta a essa pergunta está centrada na capacidade do indivíduo de designar-se como homem capaz de manter a palavra dada: "A palavra mantida afirma a manutenção do si que não se deixa inscrever, como o caráter na dimensão de alguma coisa em geral, mas unicamente naquela do quem?" (1991: 148). Aqui, ipseidade e mesmidade deixam de coincidir. Trata-se da dimensão reflexiva do $s i$ - como "eu" me reconheço e como sou reconhecido pelo 
"outro". A identidade-ipseidade é atestada pela figura da "promessa", da "palavra dada", é o Dasein do ser, sua forma de estar no mundo. Estar no mundo é uma preocupação (souci), faz de nós inquietação. Para Heidegger, exatamente, porque o ser-aí é, em essência, inquietação que podemos interpretar o ser do sendo disponível como preocupação, e o ser em coexistência com o "outro", de tal forma que o "outro" último se encontre no interior do mundo como assistência.

O espaço público sempre se apresentou como vitrine humana, onde a relação entre identidade e alteridade está exposta. E só se pergunta pela identidade quando esta está em crise, como afirmou Zygmunt Bauman (2005). E a crise da identidade teve início na era capitalista com a "complexidade do mundo moderno e com a tomada de consciência de que o núcleo interior do sujeito não era autônomo nem auto-suficiente, mas formado na relação com pessoas, sentidos e símbolos" (HALL, 2003: 11). Tanto Stuart Hall quanto Bauman identificam na modernidade tardia, que sofre com os efeitos da globalização, a maior crise da identidade, que deu lugar à fragmentação desta, ao multiculturalismo, às comunidades virtuais, ao fundamentalismo e às pluralidades identitárias.

Em tempos de modernidade líquida, "o mundo é uma ilusão, onde a angústia, a dor e a insegurança, causadas pela vida em sociedade, exigem uma análise paciente e contínua da realidade e do modo como os indivíduos estão nela inseridos" (VECCHI apud BAUMAN, 2005: 8-9). Os objetos de análise de Bauman são bastante heterogêneos e representam, em última instância, os discursos dos espaços públicos: os produtos das culturas de massa, de alta cultura, os artigos de grandes jornais, os slogans publicitários e as reflexões filosóficas, entre outros. Bauman observa que as pessoas, em busca de identidade, tentam alcançar a dimensão do ipse, mas sem sucesso, pois se tornam

conscientes de que o "pertencimento" e a "identidade" não têm solidez de uma rocha, não são garantidos para toda a vida, são bastante negociáveis e revogáveis, e de que as decisões que o próprio indivíduo toma, os caminhos que percorre, a maneira como age - e a determinação de se manter firme a tudo isso - são fatores cruciais tanto para o "pertencimento" quanto para a "identidade" (2005: 17, grifos das autoras).

O comentário de Bauman é exemplar em expor o equívoco, visto que as pessoas buscam encontrar a ipseidade, mas se perdem na pluralidade da mesmidade. A mesmidade é o suporte da ipseidade, é a porta de acesso, mas 
não é promessa, por isso a busca por "pertencimento" parece sempre ser frustrada. O equivalente à estima de si postulada por Ricoeur é, nas palavras de Bauman, o manter-se firme. A ação reflexiva, que busca avaliar, corrigir, censurar e se empenhar, é o que torna o sujeito digno da promessa. As duas identidades estão constantemente em movimento e é na mesmidade que ocorre o processo de atestação da palavra dada, da estima do si. É preciso não se perder na pluralidade das identidades-mesmidade a fim de manter, no horizonte, a promessa, que só ocorre dentro da temporalidade. Bauman detecta a dificuldade em manter-se firme e digno da promessa ao longo do tempo:

A longo prazo, as promessas de compromisso são irrelevantes... A abundância dos compromissos oferecidos, mas principalmente a fragilidade de cada um deles, não inspira confiança em investimentos a longo prazo no nível das relações pessoais ou intimas. Tampouco inspira confiança no local de trabalho, onde o status social costumava ser definido, onde a vida continua a ser ganha e os direitos de dignidade e respeito social continuam a ser obtidos e perdidos (2005: 36)

A articulação do pertencimento com os espaços públicos, vitrines de comportamentos humanos, se faz presente quando há ausência significativa, se as relações ficam no nível da mesmidade, ou promessa, quando as relações atingem o nível da ipseidade. Segundo Bauman, os lugares onde tradicionalmente o sentimento de pertencimento existia trabalho, família, vizinhança - não são mais dignos de confiança, "de modo que é improvável que façam calar a sede por convívio ou aplaquem o medo da solidão e do abandono" (2005: 37). O movimento identitário no nível da ipseidade é reflexivo. Porque alguém, em algum lugar, precisa de mim, conta comigo, então me torno digno para corresponder a essa promessa $\mathrm{e}$ para recebê-la também.

O segundo foco de investigação da filosofia ricoeuriana, a teoria narrativa em sua contribuição para a constituição do $s i$, é estruturada em quatro tópicos: (i) a constatação de que a compreensão do si é uma interpretação, que encontra na narrativa, entre outros signos e símbolos, uma mediação privilegiada; (ii) a dialética entre a constituição da ação e a constituição do si se articula em três vértices - descrever, narrar e prescrever; (iii) a teoria narrativa só faz verdadeiramente mediação entre a descrição e a prescrição se a ampliação do campo prático e a antecipação de considerações éticas estão implicadas na própria estrutura de narrar; (iv) as narrativas ficcionais nunca 
são eticamente neutras, ao contrário, representam um vasto laboratório onde são feitas escolhas, julgamentos de aprovação e de condenação, e avaliações de toda a ordem. A identidade pessoal se define a partir de quatro questões: - Quem fala? - Quem age? - Quem se conta (narra)? - Quem é o sujeito moral da imputação? São essas questões o ponto de contato entre a identidade pessoal e a identidade narrativa. Em cada uma delas está implícito, na resposta, o interlocutor e/ou leitor, e é na reflexividade do eu em relação ao outro que se dá a dimensão ética das narrativas.

O entendimento de que a construção da identidade se dá na narrativa não é unicamente de Ricoeur. Hall, por exemplo, afirma que se há a impressão de uma identidade unificada desde o nascimento até a morte é porque os indivíduos constroem uma cômoda estória sobre si mesmos (HALL, 2000), mas essa narrativa plenamente unificada não passa de fantasia, reflexo do anseio pela identidade-ipseidade. Há nessa narrativa aparentemente coerente uma eleição significativa das ações e dos agenciamentos dos fatos, realizada pelo sujeito, a fim de construir uma identidade, como mesmidade e como ipseidade. Esse mesmo processo de construção da narrativa pessoal se reproduz no nível mais amplo da cultura e da história de uma nação:

Uma cultura nacional é um discurso - um modo de construir sentidos que influencia e organiza tanto nossas ações quanto a concepção que temos de nós mesmos. As culturas nacionais, ao produzir sentidos sobre a 'nação', sentidos com os quais podemos nos identificar, constroem identidades. Esses sentidos estão contidos nas estórias que são contadas sobre a nação, memórias que conectam seu presente com seu passado e imagens que dela são construídas (HALL, 2000: 50-51).

Considerar que a identidade nacional também é uma narrativa onde identidades são construídas, onde os agenciamentos dos fatos e as peripécias, como na tragédia, definem a impressão que se tem dessa nação, direciona as considerações até então feitas acima para a dimensão ética das linguagens e para o entendimento do papel do Estado enquanto autor dessa narrativa. $\mathrm{O}$ princípio da investigação sobre a dimensão ética da narrativa está atrelado à noção de responsabilidade postulada tanto por Bakhtin quanto por Paul Ricoeur, como se verá na próxima seção.

\section{DIMENSÕES ÉTICAS DAS LINGUAGENS}

Esta seção explora a dimensão ética existente/constitutiva da relação dos sujeitos consigo mesmos, com os outros e com os discursos. Trata-se 
de apresentar as perspectivas bakhtiniana e ricoeuriana acerca da noção de responsabilidade, estando (i) a primeira vinculada, por um lado, à relação existente entre o mundo da vida e o mundo da cultura/habitável e, por outro, às relações dialógicas entre os sujeitos; (ii) e a segunda à relação entre identidades idem e ipse e alteridade.

Para Bakhtin, a solução para o problema da unidade entre o mundo da cultura e o mundo da vida está na questão da responsabilidade do ato, que é único e singular. A unidade entre, por um lado, a dimensão do idêntico, do pensamento teórico e da produção artística e, por outro, do singular, do ato e da experiência se dão por aquilo que Bakhtin chama de responsabilidade.

Note-se que os aspectos de singularidade e de repetição que definem a dimensão semântica da linguagem, conforme vistos na seção 2 , se caracterizam pela tensão existente entre a estabilidade (os sentidos dicionarizados) e a novidade (o tema). A relação entre essas duas dimensões - estabilidade e abertura - pode ser transposta ao que Bakhtin definiu como o mundo da cultura (das representações, objetificações, teorizações) e o mundo da vida (do ato único, singular e vivido). $\mathrm{O}$ ato vivido, ao ter seu sentido teorizado pela ciência, filosofia, história ou estética, passa a assumir um valor abstrato, distante do que era enquanto experiência. Esses dois mundos, segundo Bakhtin, se unem pelas duas faces da responsabilidade: (i) em relação ao significado abstrato (mundo da cultura - responsabilidade especial); (ii) em relação ao evento único (mundo da vida - responsabilidade moral). Nas palavras de Bakhtin:

E a responsabilidade especial [...] deve ser trazida (deve entrar) em comunhão com a responsabilidade moral única e unitária como um momento constituinte dela. Esse é o único meio pelo qual a perniciosa divisão e não-interpenetração entre cultura e vida poderia ser superada. (1993: 20)

Essa comunhão não é definível ou explicada pelo mundo da cultura ou do conhecimento teórico, dado que a dimensão epistemológica, ao objetivar o ato único e singular da vida, o destitui de sua singularidade e unicidade. A conexão entre a cultura e a vida se dá pela não-indiferença da ação responsável, que significa que "a responsabilidade pelo ato é, acima de tudo, responsabilidade pelo outro e minha unicidade é a impossibilidade de abdicar dessa responsabilidade" (PONZIO, 2008: 39).

A responsabilidade envolve a compreensão por parte dos sujeitos e a relação dialógica com o outro como constitutiva do eu. Note-se que essa relação, para Paul Ricoeur, define a identidade-ipseidade. Por compreensão, 
Bakhtin entende: "compreender um objeto é compreender meu dever em relação a ele (a atitude ou posição que devo tomar em relação a ele), isto é, compreendê-lo em relação a mim mesmo [...] e isso pressupõe minha participação responsável, e não uma abstração de mim mesmo" (1993: 35). Trata-se, portanto, de uma compreensão ativa. Toda compreensão é ativa porque sempre encontra seu amadurecimento na resposta do outro, e é essa compreensão - em que se dá o encontro de pontos de vista, entonações e horizontes sociais diferentes - que permite a ampliação, a ressignificação, a mudança semântica e o surgimento do novo. A relação dialógica entre os participantes, que se estabelece na comunicação socioverbal, se torna a arena onde diferentes matizes ideológicos polemizam, convergem, divergem, etc., estabelecendo entre si relações dialógicas e semânticas.

Resumindo, na abordagem bakhtiniana, o espaço de criatividade e de liberdade da língua e do processo de constituição das identidades se localiza nessa tensão existente entre a dimensão estável, previsível, repetível e cristalizada (da língua e das identidades, que envolve o mundo da cultura) e a dimensão aberta, instável, porosa, impermeável e fronteiriça (da língua e das identidades, que envolve o mundo da vida). É nesse espaço que as possibilidades do novo e do diferente se localizam, viabilizando a abertura dos sentidos para novas leituras e interpretações do/no mundo e a possibilidade de os sujeitos inventarem novas formas de intervenção no mundo e de relação consigo e com os outros. Estar nesse espaço de abertura exige que os sujeitos assumam a responsabilidade (na qual a relação euoutro é fundante) pelos enunciados, discursos, saberes e práticas que os interpelam e constituem no mundo da vida e da cultura.

Para Ricoeur, a responsabilidade é o signo da relação entre a identidade e a alteridade, visto que é o outro que interpela a responsabilidade do sujeito e essa não seria reconhecida como tal sem uma estima do si. Bauman lembra que o princípio de responsabilidade é o primeiro ato de qualquer envolvimento na vida pública. O reconhecimento éum elemento fundamental para se pensar a ética na sociedade atual, e por consequência, nos espaços públicos. Todo o trabalho de Ricoeur sobre o conceito do reconhecimento, notadamente na obra Parcours de la reconnaissance, tem implicação ética e vai ao encontro de sua proposição da perspectiva ética, articulada em três pontos: (i) o desejo da vida boa, (ii) com e para os outros, (iii) dentro de instituições justas (1991:202). Reconhecer, em primeiro plano, é reconhecer no outro o desejo da vida boa, e também as ações tomadas nessa direção. Por conseguinte, o que importa é a ação de eleição da boa ação, que visa a alcançar a vida feliz, como afirmou Aristóteles, em A poética: 
Com efeito, a tragédia é representativa [mimesis] não de homens, mas de ação, de vida [bion] e de felicidade (a infelicidade também reside na ação), e o fim visado [télos] é uma ação [práxis tis], não uma qualidade [ou poiotés]; ora, é consoante a seu caráter que os homens têm esta ou aquela qualidade, mas é segundo suas ações que são felizes ou o contrário (apud RICOEUR, 1991: 181).

Reconhecer, portanto, dentro da narrativa ficcional, é reconhecer o valor da ação. O reconhecimento, nesse caso, não está distante do elemento estrutural, de mesmo nome, da tragédia, que não representa a aniquilação da dor do herói trágico, mas sim o apaziguamento desta pelo sentido e pela verdade desvelada. Por outro lado, há também exemplos de reconhecimentos na epopeia, basta lembrar que Ulisses, na Odisséia, foi reconhecido pela cicatriz, sua marca corporal, sua identidade-mesmidade, mas o que foi acessado naquele momento por sua serva, como observou Ricoeur, foi sua identidade-ipseidade. Nesse sentido, reconhecer a verdade e reconhecer a promessa são formas de acesso à identidade-ipse, à identidade ética, por natureza. Como observou Bauman, "Reconhecimento' pode ser aquilo que mais faça falta a um ou outro grupo dos bem-sucedidos - a única coisa que parece estar faltando no inventário rapidamente preenchido por fatores da felicidade" (2005: 43). Fatores que não têm nenhuma relação com os reais valores da identidade-ipseidade.

Considerando que tanto a identidade pessoal como a identidade narrativa tem relação com a permanência no tempo, e que o acesso à identidade-ipseidade passa pela identidade-mesmidade, pode-se afirmar que a identidade narrativa mantém juntas as duas extremidades da corrente - a permanência no tempo do caráter e da manutenção do si. É, igualmente, no plano do reconhecimento que se tem a dimensão do viver-com e do viver-por, afinal, reconhecer no outro o desejo da vida boa e a promessa vers l’autre é se reconhecer inserido nessa dialética do agir humano; é se reconhecer com no mundo habitável da obra. O terceiro elemento do slogan da sabedoria prática postulada por Ricoeur - dentro de instituições justas - implica a avaliação do papel do Estado enquanto autor da narrativa de uma nação.

A reflexividade dos pronomes pessoais, que se legitima, eticamente, no designar-se a si mesmo como sujeito da imputação moral, também se estende aos impessoais cada um, qualquer um e o a gente, que caracterizam o "terceiro". O Estado, na figura do terceiro - instituições justas - foi, assim como a identidade pessoal, afetado pela globalização, que é a responsável, na opinião de Bauman, pela transformação que afetou as estruturas estatais, as 
condições de trabalho, as relações entre os Estados, a subjetividade coletiva, a produção cultural, a vida quotidiana e as relações entre o eu e o outro. $\mathrm{O}$ Estado, quando não assume o papel da instituição superior que organiza e estabiliza as relações interpessoais, falha com a sua identidade-ipseidade, a responsabilidade não é assumida e a ausência de sua função é sentida em todas as instâncias da sociedade:

As pessoas em busca de identidade encontram pouca segurança, para não falar em plenas garantias dos poderes do Estado. Recordando a famosa tríade dos direitos de Thomas Marshall: os direitos econômicos agora estão fora das mãos do Estado, os direitos políticos que ele pode oferecer são estritamente limitados e circunscritos àquilo que Pierre Bourdieu batizou de pensamento único do livre mercado neoliberal plenamente desregulado, enquanto os direitos sociais são substituídos um a um pelo dever individual do cuidado consigo mesmo e de garantir a si mesmo vantagem sobre os demais (BAUMAN, 2005: 34).

A fragmentação da identidade pessoal é reflexo da fragmentação da identidade do Estado. A situação é caótica tornando o discurso sobre a ética uma utopia. Stuart Hall, ao comentar o fundamentalismo islâmico, indica o fracasso dos estados islâmicos em garantir o pertencimento, a responsabilidade e a promessa aos indivíduos de suas sociedades: "Em condições de extrema pobreza e relativo subdesenvolvimento econômico [...], a restauração da fé islâmica é uma poderosa força política e ideológica mobilizadora e unificadora" (2003: 95). Onde o Estado não assume suas funções e desampara aqueles que contam com sua proteção, outros sistemas, que se apresentam como segurança, como pertencimento, enfim, como identidade-ipseidade, assumem o lugar vago.

\section{CONSIDERAÇÕES FINAIS}

As considerações feitas neste artigo trataram da relação entre o espaço público e as linguagens, iniciando a discussão com uma apresentação dos elementos fundamentais do diálogo - os atos responsivos, a réplica, as alternâncias dos sujeitos, as condições de comunicação, as funções e os atos de linguagem - para em seguida investigar a relação entre os atos de linguagem, as ações e o discurso. Na sequência, todos esses elementos foram articulados à noção de ideologia e de significação, sendo os espaços públicos tidos como o locus da relação entre identidade e alteridade. Essa relação exigiu uma exposição mais detalhada da dupla estrutura da identidade, enquanto mesmidade e ipseidade, sendo esta última a porta de entrada para a discussão acerca da ética. 
As linguagens estão dispostas tanto no mundo da vida (onde circulam as ideologias do cotidiano), como no mundo da cultura, ou mundo habitável, e é por isso que elas são, igualmente, por analogia aos espaços públicos, o locus de discussão da dimensão ética do agir humano. Problematizar as dimensões do eu e do outro, dispostos nesses ambientes confluentes e reflexivos - espaço público e linguagem -, implicou as considerações sobre o terceiro - o Estado. A relação entre o eu, o outro e o Estado encaminha o olhar para a dimensão do nós. O senso de coletividade implícita no nós deixa de pensar esses elementos de forma fragmentada e desconexa para articular todos os supracitados em uma dimensão real, concreta, que subsidia as linguagens e os espaços públicos. Por fim, é com o acento no pronome "coletivo" que esse texto se encerra com as palavras de Bauman:

Curto e grosso: ou nadamos juntos ou afundamos juntos. Creio que pela primeira vez na história da humanidade o auto-interesse e os princípios éticos de respeito e atenção mútuos de todos os seres humanos apontam na mesma direção e exigem a mesma estratégia. De maldição, a globalização pode até transformar-se em benção: a "humanidade" nunca teve uma oportunidade melhor! Se isso vai acontecer, se a chance será aproveitada antes que se perca, é, porém, uma questão em aberto. A resposta depende de nós (2005: 95).

\section{REFERÊNCIAS BIBLIOGRÁFICAS}

ARENDT, Hannah. A condição humana (1958). Trad. Roberto Raposo. 10. ed. Rio de Janeiro: Forense Universitária, 2005.

BAKHTIN, Mikhail. A cultura popular na Idade Média e no Renascimento - o contexto de François Rabelais (1940; 1965). Trad. Yara F. Vieira. 5. ed. São Paulo: Hucitec, 2002.

BAKHTIN, Mikhail. Estética da criação verbal. Trad. Paulo Bezerra. 4. ed. São Paulo: Martins Fontes, 2003a.

BAKHTIN, Mikhail. O discurso no romance (1934-35). In: BAKHTIN, Mikhail. Questões de literatura e de estética: a teoria do romance. Trad. Carlos Vogt e Eny Orlandi. 4. ed. São Paulo: Unesp, 1998. p. 71-164.

BAKHTIN, Mikhail. Os gêneros do discurso (1952-53). In: BAKHTIN, Mikhail. Estética da criação verbal. Trad. Paulo Bezerra. 4. ed. São Paulo: Martins Fontes, 2003b. p. 277-326. 
BAKHTIN, Mikhail. Para uma filosofia do ato (1919-1921). Tradução inédita, sem revisão, destinada ao uso didático de Carlos Alberto Faraco e Cristivão Tezza do texto da edição americana Towards a Philosophy of the Act. Austin: University of Texas Press, 1993.

BAKHTIN, Mikhail; VOLOSHINOV, Valentin Nikolaevich. Marxismo e filosofia da linguagem (1929). Trad. Michel Lahud e Yara F. Vieira. São Paulo: Editora Hucitec, 1988.

BAKHTIN, Mikhail; VOLOSHINOV, Valentin Nikolaevich. Ofreudismo (1927). Trad. Paulo Bezerra. São Paulo: Perspectiva, 2004.

BAUMAN, Zygmunt. Identidade: entrevista a Benedetto Vecchi. Trad. Carlos Alberto Medeiros. Rio de Janeiro: Jorge Zahar, 2005.

HALL, Stuart. A identidade cultural na pós-graduação. 3. ed. Rio de Janeiro: DP\&A, 2003.

PONZIO, Augusto. A revolução bakhtiniana. São Paulo: Contexto, 2008.

RICOEUR, Paul. Du texte à l'action - essais d'herméneutique II. Paris: Seuil, 1986.

RICOEUR, Paul. La métaphore vive. Paris: Seuil, 1975.

RICOEUR, Paul. O si-mesmo como um outro. Trad. Lucy Moreira César. Campinas: Papirus, 1991.

RICOEUR, Paul. Teoria da interpretação: o discurso e o excesso de significação. Lisboa: Edições 70, 2000. 